\title{
Introduction of Key Feature Problem Based Questions in Assessment of Dental Students
}

\section{IJCRR}

Section: Healthcare

Sci. Journal Impact

Factor: 6.1 (2018)

ICV: $90.90(2018)$

Scopus'

\section{Preethi Sharma ${ }^{1}$, Punit Fulzele², Minal Chaudhary ${ }^{3}$, Madhuri Gawande ${ }^{3}$, Swati Patil ${ }^{4}$, Alka Hande ${ }^{3}$}

\begin{abstract}
'Assistant Professor, Department of Oral Pathology and Microbiology, Sharad Pawar Dental College and Hospital, DMIMS (Deemed to be University), Sawangi (Meghe), Wardha; ${ }^{A}$ Associate Professor, Department of Pedodontics, Sharad Pawar Dental College and Hospital, DMIMS (Deemed to be University), Sawangi (Meghe), Wardha; ${ }^{3}$ Professor, Department of Oral Pathology and Microbiology, Sharad Pawar Dental College and Hospital, DMIMS (Deemed to be Uuniversity), Sawangi (Meghe), Wardha; ${ }^{4}$ Associate Professor, Department of Oral Pathology and Microbiology, Sharad Pawar Dental College and Hospital, DMIMS (Deemed to be University), Sawangi (Meghe), Wardha.
\end{abstract}

\section{ABSTRACT}

Objectives: The aim of the study was to assess the individual's clinical decision-making ability through Key feature problems and to compare Key feature problems with conventional level II based questions among third-year undergraduate dental students in the subject Oral Pathology.

Study design: The study is an interventional educational research.

Results: Comparisons between groups A and B were carried out by using descriptive and inferential statistics using Student's unpaired t-test and Cronbach's alpha method of reliability. The software used in the analysis was SPSS 26.0 version and $p<$ 0.05 is considered as the level of significance. The mean score being $8.93 \pm 0.93$ for group A-Key feature problem and $7.05 \pm 1.28$ for group B-Conventional Level II. The difference between the two scores was found to be statistically significant with $p$-value less than 0.05 . The reliability of Key feature problems was 0.98 .

Conclusion: It was observed in our study that students who were exposed to Key feature problem performed better in decision making skills. The Key feature problems do not entirely rely on the factual knowledge but it has the ability to apply the knowledge within case-based scenarios comprising of crucial elements and requiring critical decisions at specific decision points during the judgement and management of the problem.

Key Words: Clinical decision-making, Key features, Key feature problem

\section{INTRODUCTION}

The essential requirement of health professional education is an assessment of clinical competence. The major responsibilities of medical schools are teaching and assessing medical student's skills. The most common approach for evaluating skills is through written documentation and direct observation of clinical performance. The concept of key feature was first introduced by Bordage and Page in the year 1987. ${ }^{1}$ The most preferred format for the assessment at that time was the written format of patient management problem (PMP) that comprised of case-based scenario with sections of items which recalled the responses of candidates with respect to case history taking, general examination, clinical diagnostic techniques, investigations, and the diagnosis. This format was made popular by its high authenticity and face validity.
It still had few serious drawbacks such as very low reliability of the test and thoroughness of data gathering was rewarded rather than the ability to make appropriate decisions. ${ }^{1}$

To forbid these drawbacks, Page and Bordage ${ }^{2}$ suggested that every clinical situation has few uncommon, critical elements in reaching a diagnosis. These elements individually or as a whole play an essential part in the resolution of the problem. These elements were named as key features. ${ }^{2}$ Thus, a new tool for assessing clinical decision-making skills was introduced which recalled the answers from the students in relation to the key elements for the resolution of each key feature problem. ${ }^{3}$ Examining only the critical elements empowered the students to be examined on a broad range of clinical problems than was the case with the patient management problem format.

\section{Corresponding Author:}

Dr. Preethi Sharma, Assistant Professor, Department of Oral Pathology and Microbiology, Sharad Pawar Dental College and Hospital, DMIMS (Deemed to be University), Sawangi (Meghe), Wardha; Email: dr.preethisharma@gmail.com

ISSN: $2231-2196$ (Print)

Received: 25.04 .2020
ISSN: $0975-5241$ (Online)

Revised: 06.06 .2020
Accepted: 07.07 .2020
Published: 22.07 .2020 
Key feature problems mirror every day or life-threatening situations routinely experienced by a general medical practitioner. ${ }^{4,5}$ Using this format, based on the history provided one can be judged on his potentiality to arrive at a clinical diagnosis.

We are introducing the idea of a key feature problem in the written examinations of clinical decision-making skills in Oral Pathology, Sharad Pawar Dental College and Hospital, Datta Meghe Institute of Medical Sciences, (Deemed to be University), Sawangi (Meghe) Wardha with the purpose of encouraging better articulation of clinical decision-making skills.

Following are the objectives needed to accomplish

1. Introduction and sensitization of dental students and faculty with Key feature problems.

2. To assess the individual's clinical decision-making ability through Key feature problems.

3. Comparison of Key feature problems with conventional level II based questions

4. To evaluate the perception of students regarding Key feature problems.

5. Evaluation of the perception of faculty regarding Key feature problems.

\section{MATERIALS AND METHOD}

After obtaining the clearance from the Institutional ethical committee of Datta Meghe Institute of Medical Sciences (Deemed to be University), Sawangi (M), Wardha (Annexure I), 90 students of $3^{\text {rd }}$ year BDS 2017 batch were enrolled after taking written informed consent during a regular clinical posting in the Department of Oral Pathology (AnnexureII). The students were randomly divided into two groups of 45 each by the lottery method. These groups were named as Group A (Key feature Problem) and Group B (Conventional Level II). The study duration was 12 months.

The key feature problem was introduced to the faculty and the students of Group A were sensitized. The examination was conducted on key feature problems based on three topics. All the participants already had the basic theoretical knowledge about the clinical features, differential diagnosis, investigations, and management of some important oral diseases which were already taught to them in regular theory classes. The problems on key features were structured by the faculty members. Three typical clinical scenarios each with ten key features on 3 topics were structured serving as a basis for defining the key feature problems. The question format used was the Long answer menu format. The scoring of the questions within the Key feature problems was averaged so that each key feature had a maximum rating of "1", resulting in a possible maximum of 10 marks. The students of group A were assessed on key feature problems while the students of
Group B were assessed on conventional level II based questions by a similar clinical scenario.

The preparation of Key feature problem relies on the following steps:

1. Selection of a clinical problem

2. Identifying and defining the key elements for each key feature problem with a particular age group and clinical setting

3. Writing case-based scenarios and questions

4. Scoring criteria to be set for testing each key element.

Clear instructions were provided to the students before taking this type of examination. The key feature questions were evaluated by two assessors. A validated scoring key defines the answers or the responses needed to produce a score of "1" for each key feature. It also assigns a weight to each correct answer of a key feature such as the same weight of 0.25 to each of four correct answers. The use of equal weighing is preferred as the research has shown that the score reliability is not improved by the differential weighting. The incorrect answers or responses receive a score of "0" regardless of other answers for the particular question is used prudently.

- This educational research study is performed in the following steps

- Step 1-The total number of students attending for regular clinical posting comprised of 90 students. The students were randomly divided into two groups of 45 each by the lottery method. Group A-Key feature problem and Group B-Conventional Level II.

- Step 2- Pretest (validated) was conducted for Group A students. (Annexure-III)

- Step 3- The students from Group A were sensitized to key feature problem. They were instructed not to discuss anything about key feature problem and the evaluation method with Group B students. The students of Group A were exposed to key feature problem to evaluate clinical decision-making skills by providing the clinical scenario.

- $\quad$ Step 4- Post-test (validated) was conducted for Group A students. (Annexure-III)

- Step 5- For comparison and evaluation between the key feature problem and the Conventional level II method, the students of Group B were exposed to the conventional level II based questions by using the similar clinical scenarios.

- Step 6- A crossover was done for exposing all the students to both key feature problems and Conventional level II based questions concerning ethical issues.

- Step 7- Feedback from all the students and the faculty was obtained.

The students' feedback questionnaire consisted of 10 closedended items and one open-ended item. 
Faculty feedback questionnaire consisted of 5 closed-ended items and two open-ended items.

A validated pre-test and post-test questionnaire of key feature problems consisted of five open-ended questions. All of the student's responses to the pre and post-tests were scored according to the appropriateness of answers. The students were told that the survey will not affect their grades so they could feel free to express their views. Complete confidentiality was maintained for feedback questionnaire.

\section{OBSERVATIONS AND RESULTS}

The present study was undertaken to evaluate the clinical decision-making skills of Dental students using key feature problem in the subject of Oral Pathology. The total number of students enrolled in the study were 90 undergraduate $3^{\text {rd }}$ year students of Sharad Pawar Dental College (from 2017 batch). The students were divided randomly into two groups of 45 students each. The students from group A were sensitized and exposed to key feature problem in the subject of Oral Pathology to assess clinical decision-making skills. Group B was assessed by Conventional level II based questions. The scores of students from both groups were subjected to statistical analysis. The data were subjected to student's unpaired ' $t$ ' test. The comparison between scores of Group A- Key feature problem and Group B- Conventional Level II based Questions (Graph 1). The comparison between scores of pre-test and post-test for the key feature problem (Graph 2). The reliability analysis of Key feature problem (Graph 3). The mean score for each key feature was calculated. It was found that more than $90 \%$ of students were deficient in the areas of the diagnostic techniques to be carried out after the identified diagnosis. $33 \%$ of students were deficient in the areas of investigations to be carried out after the identified diagnosis. $20 \%$ of students were deficient in the areas of metastatic spread of the tumor after the identified diagnosis (Table 1). The perception of students regarding key feature problem through ten closed-ended questions and one openended question was taken (Graph 4). The perception of faculty regarding key feature problem through five closed-ended questions and one open-ended question was taken (Table 2). The findings of open-ended questions were the faculty found challenging in the identification of key features for structuring key feature problems and also challenging in the valuation of key features problems as it is more timeconsuming. They found that there is no scope for inclusion of histopathological diagram which is important as each key feature carries only one mark.

\section{DISCUSSION}

The educational systems of all the medical sciences have the responsibility to shift the medical learners from memorizing the facts to analytical reasoning and creative problem-solving. ${ }^{18}$ Clinical reasoning is defined as the process by which the clinicians or the physicians collect information regarding the problem with previous experiences and knowledge, accordingly plan and execute the interventions to address a problem. ${ }^{19}$ Here, the skills of the clinicians play an essential role in reaching a diagnosis and successful treatment of the problem. It should be taught and tested in medical schools. The key features concept relies on the idea of "case specificity". Every case has got unique key features. The approach delivers an effective deal of variability on question formatting sequels, multiple answers to questions, and marking criteria. The cases on key features are introduced to evaluate the analytical skills instead of simply recollecting the conceptual learning. Knowledge is undoubtedly important for solving any clinical case effectively; the difficulty faced by the problems on key features involves the use of factual knowledge to the settlement of a case. ${ }^{20}$

The key feature assessment tool is widely used in medical education, but the reports related to its use in the dental curriculum are not yet available where the environment is quiet the same in terms of clinical workload, teaching schedules, and a number of students.

With these fundamental needs, we tried to introduce the concept of key feature problems among the faculty, and the students of Third BDS were sensitized to the concept in the subject of Oral Pathology. A total of 90 students was selected from 3rd B.D.S and was randomly divided into two groups of 45 each by lottery method.

The students of Group A were exposed to key feature problems while Group B students were exposed to Conventional Level II based questions. The students of both Group A and Group B were assessed for clinical decision-making skills. The mean score for key feature problem was $8.93 \pm 0.93$ and the mean score for Conventional level II was $7.05 \pm 1.28$. The result of our study states that students who were exposed to key feature problem scored more marks when compared to the conventional method. This is in agreement with the study conducted by Mitra Amini et al. ${ }^{11}$ where the total score was highest for Key feature problems when compared to other tests. The students performed better in clinical decision-making skills and this is in agreement with the study conducted by Shohreh Zamani et al. ${ }^{16}$ who stated that Key feature problem is a novel evaluation tool with validity evidence to support its use in the assessment of student's clinical decision-making skills. It is important that the students follow the instructions and read the clinical scenario and its key features carefully to avoid unnecessary loss of marks. ${ }^{21}$ The reliability of key feature problems was high in our study i.e., 0.98 whereas the reliability according to the study done by Shohreh Zamani et al. ${ }^{16}$ was found to be 0.75 and according to the study done by Fischer et al. the reliability was 
$0.65 .^{22}$ In our study, the key feature problem examination was well perceived by the students. This is in agreement with the study conducted by Meike Grumer et al. ${ }^{17}$ wherein the perception of students was taken on Key feature problems and the students showed a higher level of acceptance and appreciation of the assessment tool.

The perception of students in group A was taken based on 10 closed-ended questions and one open-ended question. ${ }^{23}$ The findings were more than $90 \%$ of students agreed that the key feature problem helped them to inculcate previous knowledge, problem-solving, and clinical decision-making skills. Also, more than $90 \%$ of students agreed that the key feature problem relates closely to the problems that can arise in clinical practice. The perception of faculty was taken based on 5 closed-ended questions and two open-ended questions. The faculty found that the key feature problems mirror common or life-threatening problems typically encountered by family physicians. They also found challenges in the identification and valuation of key features. There is no scope for inclusion of histopathological diagram which is important as each key feature carries only one mark. They thought the key features of a problem resemble that of Brief answer questions (BAQ's) of Conventional Level II based questions.

\section{CONCLUSION}

It was observed in our study that students who were exposed to key feature problems performed better in decision-making skills. The key feature problems do not entirely rely on factual knowledge but it has the ability to apply the knowledge within case-based scenarios comprising of crucial elements and requiring critical decisions at specific decision points during judgment and management of the problem.

An increased emphasis can be made using this tool on teaching-learning modality around clinical reasoning and decision making skills. The learners who are lacking in these areas were analyzed and reorientation was carried out.

Acknowledgement- Authors acknowledge the immense help received from the scholars whose articles are cited and included in references of this manuscript. The authors are also grateful to authors / editors / publishers of all those articles, journals and books from where the literature for this article has been reviewed and discussed.

\section{Source of Funding-None}

\section{Conflict of interest-None}

\section{REFERENCES}

1. Bordage G, Page G. An alternate approach to PMPs, the key feature concept. In: Hart I, Harden R, eds. Further Developments in Assessing Clinical Competence. Montreal: Can-Heal Publications 1987;57-75.

2. Page G, Bordage G. The Medical Council of Canada's key features project: a more valid written examination of clinical decision-making skills. Acad Med. 1995;70:104-10.

3. Csapo, B. and J. Funke. The Nature of Problem Solving: Using Research to Inspire 21st Century Learning. OECD Publishing, Paris. 2017.

4. Page G. Writing Key Feature Problems for the Clinical Reasoning Skills Examination: a Guide for CRS Committee Members in their Understanding and Preparation of Key Feature Problems. Ottawa: Medical Council of Canada 1999.

5. Farmer EA. Writing key feature problems for general practice. Melbourne: Royal Australian College of General Practitioners 1998.

6. Rose Hatala, Geoffrey R Norman. Adapting the Key Features Examination for a clinical clerkship. Medical Education. 2002 March; 36(2):160-5.

7. Farmer, E. A. \& Page, G. A practical guide to assessing clinical decision-making skills using the key features approach. BMC. Medical Education. 2005; 39 (12), 1188-1194.

8. Elizabeth Farmer and John Hinchy. Assessing general practice clinical decision making skills. The key features approach. Reprinted from Australian Family Physician. 2005 December; Vol. 34, No. 12.

9. Trudel JL, Bordage G, Downing SM. Reliability and validity of key feature cases for the self-assessment of colon and rectal surgeons. Ann Surg. 2008 Aug; 248(2):252-8.

10. C. Nikendei, S. Mennin, P. Weyrich, B. Kraus, S. Zipfel, M. Schrauth \& J. Junger. Effects of a supplementary final year curriculum on students' clinical reasoning skills as assessed by keyfeature examination. Medical Teacher. 2009; 31:9.

11. Mitra Amini, Mohsen Moghadami, Javad Kojuri, Hamidreza Abbasi, Ali Arhami Doolat Abadi. An innovative method to assess clinical reasoning skills: Clinical reasoning tests in the second national medical science Olympiad in Iran. BMC Research Notes. 2011; 4:418.

12. Elisabeth Schaper, Andrea Tipold and Jan P Ehlers. Use of key feature questions in summative assessment of veterinary medicine students. Irish Veterinary Journal 2013; 66:3.

13. Hrynchak P, Takahashi SG, Nayer M. Key-feature questions for assessment of clinical reasoning: a literature review. Med Educ. 2014 Sep; 48(9):870-83.

14. Fok-Han Leung, Jodi Herold, Karl Iglar. Family Medicine Mandatory Assessment of Progress. Canadian Family Physician. 2016 May; Vol 62.

15. Meike Jost, Peter Brustle, Marianne Giesler, Michel Rijntjes and Jochen Brich. Effects of additional team based learning on student's clinical reasoning skills: a pilot study. BMC Res Notes. 2017; 10:282.

16. Shohreh Zamani, Mitra Amini, Seyede Zahra Masoumi, Somayeh Delavari, Mohammad Javad Namaki, Javad Kojuri. The comparison of the key feature of clinical reasoning and multiple choice examinations in clinical decision makings ability. Biomedical Research. 2017; 28 (3): 1115-1119.

17. Meike Grumer, Peter Brustle, Johann Lambeck, Silke Biller, Jochen Brich. Validation and perception of a key feature problem examination in neurology. PLOS ONE. 2019

18. Lal P. From rote to reasoning: The paradigm shift required in medical entrance examination and beyond. MAMC J Med Sci 2016;2:1-5

19. Barbara Simmons. Clinical reasoning: Concept analysis. Journal of Advanced Nursing. March 2010; 66 (5):1151-8. 
20. Shravani Deolia, Karthika Nambiar, Payal Padole, Andrea Tlau, Aditi Agrawal, Amit Reche. Dental Patient's Knowledge, Attitude and Practice of Tobacco Use and Perception Towards the Role of Dentists in Tobacco Cessation. JODRDMIMS 2018;2(4).

21. Shravani Deolia, Madhulika Hatgadkar, Sonal Deole, Trupti Rathi, Sourav Sen, Amit Reche. Dental Student's Attitude Towards Learning Communication Skills. JODRDMIMS 2019;3(2).

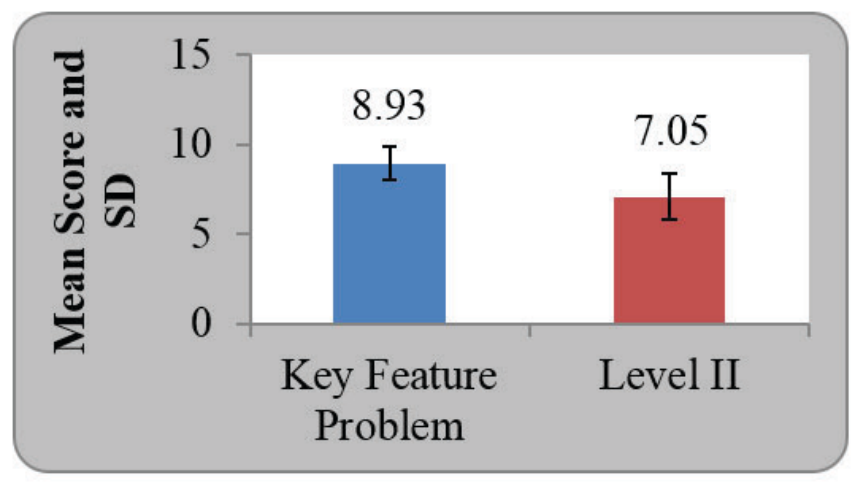

Graph 1: Comparison of scores in two groups.

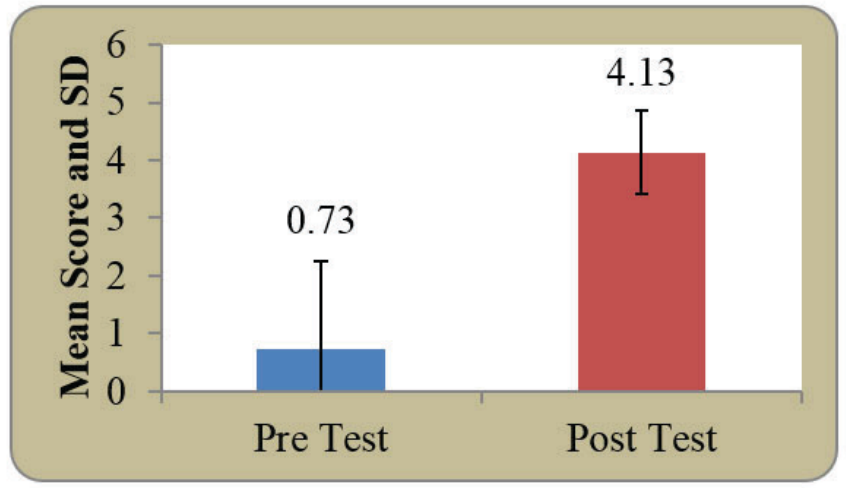

Graph 2: Comparison of pretest and posttest score.

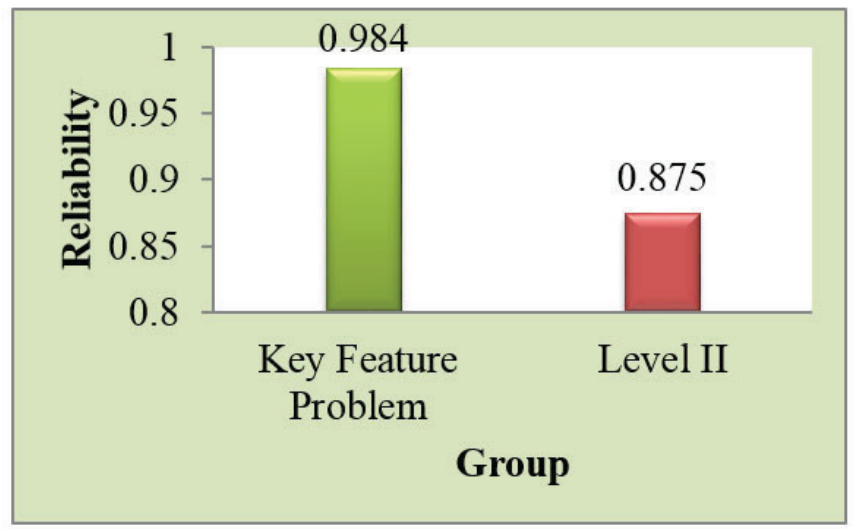

Graph 3: Reliability Analysis.
22. Fischer MR, Kopp V, Holzer M, Ruderich F, Junger J. A modified electronic key feature examination for undergraduate medical students: validation threats and opportunities. Med Teach. 2005; 27:450-5.

23. Aarati Panchbhai, Shreya Gupta. Assessment of Oral Health and Oral Hygiene Habits in Patients Visiting Rural Dental Hospital. JODRDMIMS 2019;3(4).
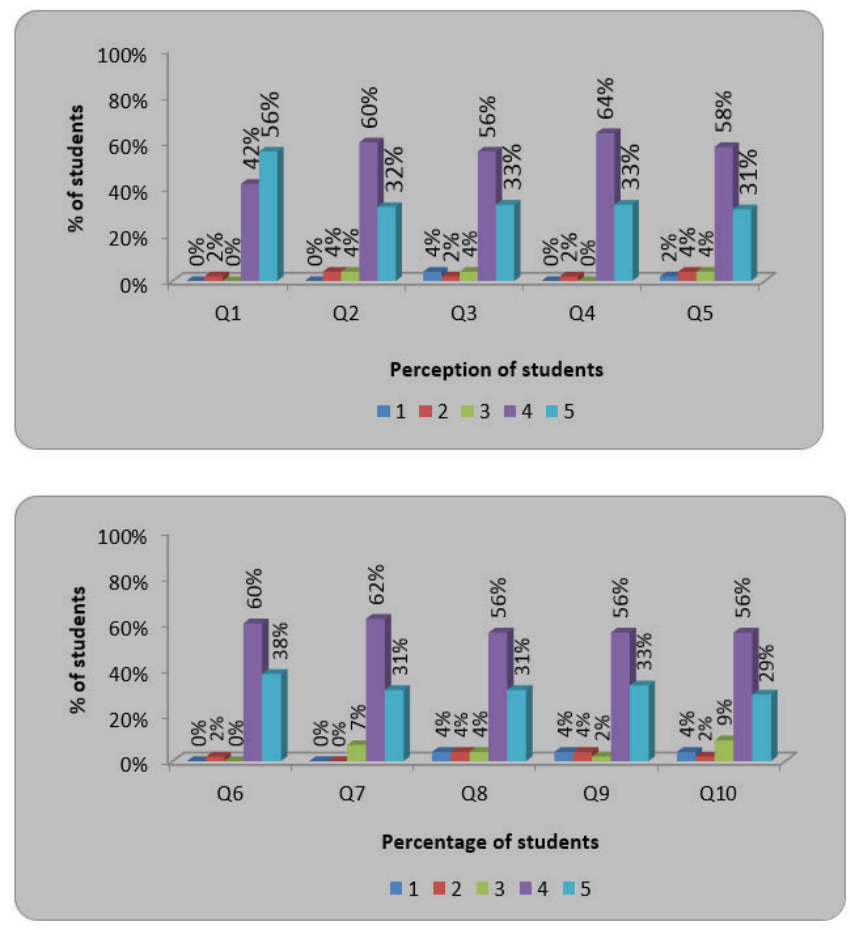

Graph 4: Perception of students regarding Key feature problem (KFP). 


\section{PERCEPTION OF STUDENTS TO KEY FEATURE PROBLEM (KFP)}

1- Strongly disagree; 2- Disagree; 3- Neutral; 4- Agree; 5- Strongly agree

\begin{tabular}{|c|c|c|c|c|c|c|}
\hline S. No. & Items & 1 & 2 & 3 & 4 & 5 \\
\hline 1. & I was instructed/ oriented about KFP before the session. & oo $(0 \%)$ & $02(2 \%)$ & oo $(0 \%)$ & $38(42 \%)$ & $25(56 \%)$ \\
\hline 2. & KFP enabled me to meet the objectives of the course. & & & & & \\
\hline 3. & KFP helped me in narrowing the differential diagnosis. & & & & & \\
\hline 4. & $\begin{array}{l}\text { KFP helped me to inculcate previous knowledge, problem solving } \\
\text { and clinical decision making skills. }\end{array}$ & & & & & \\
\hline 5 . & It increases conceptual learning \& independent critical thinking. & & & & & \\
\hline 6. & KFP relate closely to the problems that can arise in clinical practice. & & & & & \\
\hline 7 . & $\begin{array}{l}\text { I found it interesting in getting to know this kind of assessment } \\
\text { method. }\end{array}$ & & & & & \\
\hline 8. & I found KFP assessment method relatively easy in scoring marks. & & & & & \\
\hline 9 . & The time frame allotted to solve KFP was appropriate. & & & & & \\
\hline 10. & I wish to have an exam with KFP in the future curriculum. & & & & & \\
\hline
\end{tabular}

\section{ANNEXURE III}

Pre-test/Post-test

1. What is Key Feature Problem?

2. Which skills are tested by Key Feature Problem?

3. What does Key Feature Problem reflect?

4. Enlist any one advantage of Key Feature Problem

5. Enlist any one disadvantage of Key Feature Problem 